\title{
Comparison of aspiration and scintigraphic techniques for the measurement of gastric emptying rates of liquids in humans
}

\author{
E J Beckers, J B Leiper, J Davidson
}

\begin{abstract}
A comparison was made of two techniques to measure the rate of gastric emptying. A noninvasive scintigraphic technique using a gammacamera and an invasive aspiration technique based on dye dilution were performed simultaneously. Seven healthy male volunteers each consumed two different liquid meals on two separate occasions. Scintigraphic measurements were performed continuously with aspiration every 10 minutes for a total of one hour. Gastric emptying rates were expressed as slope values after semilog linearisation of the emptying curves. Agreement between the two methods was assessed from the individual differences and mean of the two techniques, as well as from the geometric mean, including $95 \%$ limits of agreement. The scintigraphic technique gave a $70 \%$ slower emptying rate than the dye dilution technique. However, the $95 \%$ limits of agreement are large $(1.56$ to 0.30$)$, reflecting the small sample size and the large coefficient of variation in the techniques used.
\end{abstract}

Many studies comparing the gastric emptying rates of various meals under different conditions have been performed. Comparing the results from different laboratories is difficult as many different techniques ${ }^{1-9}$ are used and it is not clear whether systematic or random variations occur as a result of the method used. All techniques have their specific advantages and drawbacks which, along with operator expertise and availability of apparatus, will determine the method a laboratory chooses to use. The present study was undertaken to compare a non-invasive scinti-

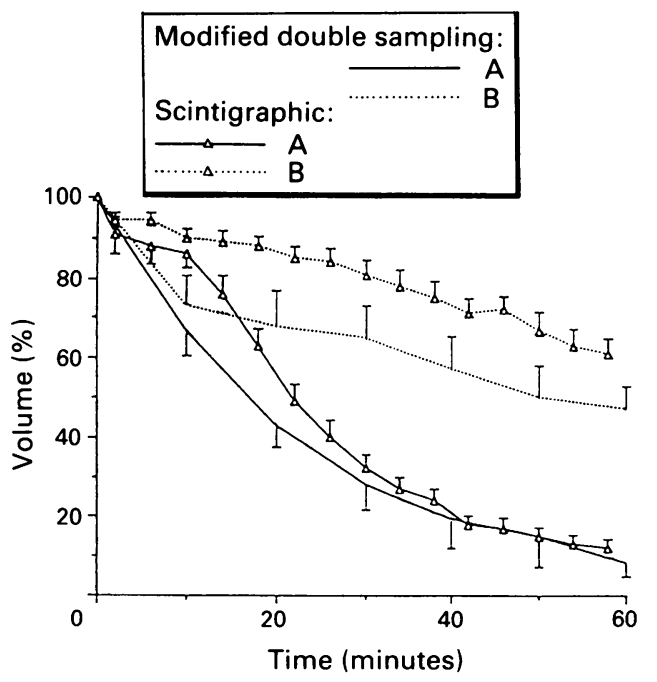

Slope values for all subjects, differences, mean, SD and SEM of gastric emptying curves after semilog linearisation

\begin{tabular}{|c|c|c|c|c|c|}
\hline \multirow[b]{2}{*}{ Subject } & \multirow[b]{2}{*}{ Drink } & \multicolumn{2}{|l|}{ Slope } & \multirow{2}{*}{$\begin{array}{l}\text { Difference } \\
\text { scint-DS }\end{array}$} & \multirow{2}{*}{$\begin{array}{l}\text { Mean } \\
\text { scint-DS }\end{array}$} \\
\hline & & $D S$ & Scint & & \\
\hline A & A & -0.0087 & -0.0024 & 0.0062 & -0.0055 \\
\hline B & A & -0.0207 & -0.0153 & 0.0054 & -0.0180 \\
\hline C & A & -0.0156 & -0.0146 & 0.0010 & -0.0151 \\
\hline D & & -0.0189 & -0.0153 & 0.0036 & -0.0171 \\
\hline E & A & -0.0305 & -0.0192 & 0.0113 & -0.0248 \\
\hline $\mathrm{F}$ & A & -0.0325 & -0.0288 & 0.0036 & -0.0307 \\
\hline G & A & -0.0228 & -0.0180 & 0.0048 & -0.0204 \\
\hline Mean & A & -0.0214 & -0.0162 & 0.0051 & -0.0188 \\
\hline SD & A & 0.0083 & 0.0078 & 0.0032 & 0.0079 \\
\hline SEM & A & 0.0031 & 0.0030 & 0.0012 & 0.0030 \\
\hline A & B & -0.0040 & -0.0028 & 0.0013 & -0.0034 \\
\hline B & B & -0.0040 & -0.0023 & 0.0017 & -0.0031 \\
\hline C & B & -0.0119 & -0.0045 & 0.0074 & -0.0082 \\
\hline D & B & -0.0059 & -0.0044 & 0.0015 & -0.0052 \\
\hline E & B & -0.0070 & -0.0053 & 0.0017 & -0.0061 \\
\hline $\mathrm{F}$ & B & -0.0028 & -0.0015 & 0.0013 & -0.0021 \\
\hline & B & -0.0047 & -0.0043 & 0.0003 & -0.0045 \\
\hline Mean & B & -0.0057 & -0.0036 & 0.0022 & -0.0047 \\
\hline SD & B & 0.0030 & 0.0014 & 0.0023 & 0.0021 \\
\hline SEM & B & 0.0011 & 0.0005 & 0.0009 & 0.0008 \\
\hline
\end{tabular}

DS=modified double sampling technique. Scint $=$ scintigraphy.

graphic technique ${ }^{6}$ with an invasive dye dilution technique. $^{2-4}$ Scintigraphic studies employ a gammacamera which externally monitors the emptying of radionuclide beverages ${ }^{6}$ from the stomach. As this method allows almost continuous monitoring, the shape of the emptying curve can be well defined. A disadvantage, however, is that a clear and well defined picture of the stomach has to be obtained, restricting this technique to studies in a stable position - that is, at rest only. The modified double sampling technique, in contrast, can be conducted even during intense exercise, making it of interest to exercise physiologists. ${ }^{+}$In addition, this technique allows the rate of gastric secretion to be calculated. An obvious disadvantage is the need for intubation of the stomach and the consequent discomfort for the volunteer or patient. Both techniques are widely used in clinical and research settings, and the aim of the present study was to compare them using liquid test meals.

\section{Methods}

Seven healthy male volunteers (mean (SD) age 29 (12) years, weight 72 (7) kg, height 178 (4) $\mathrm{cm}$ ), with no history of gastrointestinal disease, who were all familiar with gastric intubation and testing, were asked to participate in two gastric emptying tests each. Approval for the study was obtained from the Joint Ethical Committee of Grampian Health Board and the University of Aberdeen. The purpose of the study and the procedures were explained to the subjects before their written consent was obtained. 
Drink A

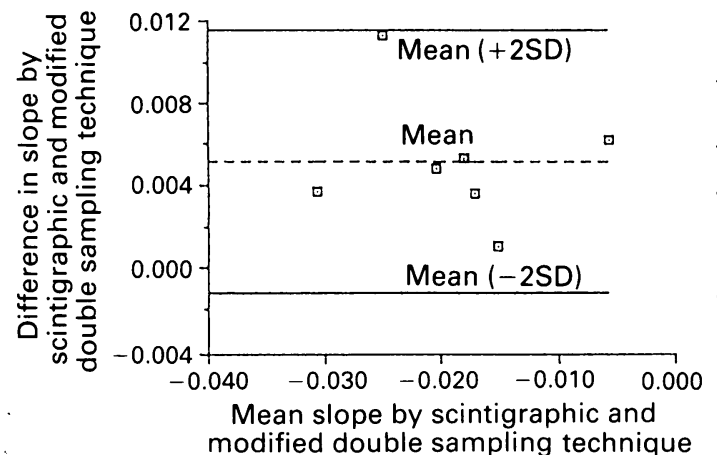

Drink B

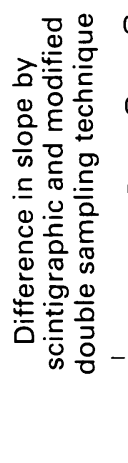

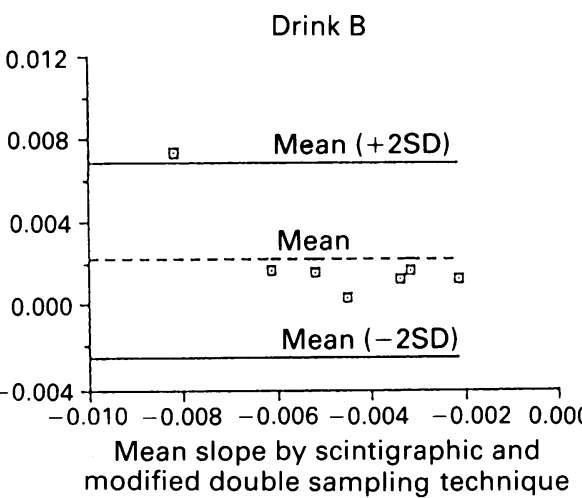
modified double sampling technique

Figure 2: Difference against mean for slope values of scintigraphic and modified double sampling techniques including $95 \%$ limits of agreement ( $\pm 2 S D)$.

DAILY PROTOCOL

Subjects arrived at the laboratory having fasted for at least eight hours. A gastroduodenal catheter (Levin type, $\mathrm{CH} 14,125 \mathrm{~cm}$, Vygon Steriel NV, Brussels) was placed in the stomach and the subjects stood in front of the gammacamera. The test meal $(8 \mathrm{ml} / \mathrm{kg}$ body weight) was administered via the catheter, mixed with the fasting gastric contents and a starting sample was taken so the initial gastric contents could be accounted for using modified double sampling technique at time zero. Time zero was taken as the moment when all of the test meal had been administered. Samples for the determination of gastric secretion and emptying were taken at 10 minute intervals for 1 hour. This technique has been described in detail elsewhere ${ }^{4}$ and is based on George. ${ }^{2}$ For scintigraphic data collection, subjects were imaged using a low energy general purpose collimator; the camera used was an IGE 500 A Maxicamera linked to a Dec PDP II computer. Dynamic scintigraphy was performed continuously with the subjects in a standing position. Fifteen anterior and 15 posterior abdominal scans were recorded alternately over 60 seconds. Total measuring time was one hour. A region of interest was drawn around the stomach and the arithmetic mean counts of the anterior and posterior projections in that region, after correction for decay, was calculated and used to determine the emptying rate of the test meals. ${ }^{10}$ Both techniques were performed simultaneously.

\section{TEST MEALS}

Two different liquid test meals were used. Solution A is an isotonic $(296 \mathrm{mOsm} / \mathrm{kg})$ primarily disaccharide (carbohydrate concentration $72 \mathrm{~g} / \mathrm{l}$, energy density $1 \cdot 3 \mathrm{MJ} / \mathrm{l}$ ) drink with added minerals, known from previous experiments ${ }^{11}$ to empty fast. Solution B is a carbonated hypertonic $(600 \mathrm{mOsm} / \mathrm{kg}$ ) glucose polymer (carbohydrate concentration $193 \mathrm{~g} / 1$, energy density $3 \cdot 1$ MJ/l) drink presumed to empty slowly. Each test meal was labelled with two non-absorbable markers, ${ }^{99 m}$ Technetium diethylene triamine penta-acetic acid at a dose of $2 \mathrm{MBq}$ for scintigraphy and $15 \mathrm{mg} / \mathrm{l}$ phenolred for double sampling. Tests with drink $A$ and $B$ were performed at the same time of day and one week apart for each subject to account for any circadian variation. ${ }^{12}$
DATA ANALYSIS

Data were analysed after semilog transformation of the gastric emptying curve and emptying rates were expressed as slope values of the resulting straight line. Gastric emptying data are commonly presented as half emptying time $\left(t^{1 / 2}\right)$ because this is an easily interpreted parameter describing the overall emptying curve which is of physiological relevance ${ }^{1314}$ and not just single points of the curve. In this study the data are expressed as the slope value after semilog linearisation of the gastric emptying curve. This parameter also describes the whole of the emptying curve. Drink B emptied at such a slow rate that $t^{1 / 2}$ would have been in the range $150-200$ minutes, well outside the 60 minute actual measuring range. For statistical comparison of the slope values, individual differences, and the mean of the two techniques were calculated, as well as the geometric mean after log transformation, and the $95 \%$ limits of agreement as suggested by Bland and Altman. ${ }^{15}$ The statistical difference in emptying rates between drink $A$ and $B$ are expressed as $p$ values calculated from the Wilcoxon signed rank test. All data in the text, tables, and figures are mean (SEM), unless indicated as SD.

\section{Results}

The mean time course of gastric emptying for the two drinks and both techniques is shown in Figure 1. Individual data are shown in the Table as slope values after semilog linearisation of the gastric emptying curve. The mean accuracy of the fit used, expressed as the correlation coefficient $r$, is 0.95 for drink $A$ and 0.89 for drink $B$ in the double sampling technique experiment and 0.96 and 0.90 respectively for the scintigraphy data. Also presented in the Table are the individual differences between the two techniques and their means. Figure 2 is a scattergram of the difference against the mean of the two techniques for drinks A and B. Statistical evaluation of the results (Wilcoxon signed rank test) confirmed that drink A was emptied from the stomach at a faster rate than drink $B$, and this was so for both techniques (double sampling $\mathrm{Z}=-2 \cdot 366, \mathrm{p}=0.02$; scintigraphy $\mathrm{Z}=-2 \cdot 197$, $p=0.03$ ). On average, at the end of the 60 minute measuring period more than $60 \%$ of the initial bolus remained in the stomach when drink $B$ was 
given, but only $15 \%$ of drink A remained. The mean difference in slopes between the two techniques for drink $A$ is 0.0051 with $95 \%$ limits of agreement of +0.0115 to -0.0012 and for drink B 0.0021 with limits of +0.0068 to -0.0025 . After $\log$ transformation of the data the geometric mean was calculated: drink A 0.68 (95\% limits of agreement 1.56 to 0.30 ); drink B $0.64(95 \%$ limits $1 \cdot 14$ to $0 \cdot 36)$.

\section{Discussion}

Both techniques indicate that there is a large interindividual variability in the gastric emptying rate, as reflected by the high SEM values of the double sampling technique and scintigraphy in the Table. This, however, represents a real difference between individuals rather than a lack of accuracy of the two methods. Two drinks were used to compare the two techniques in order to investigate whether there was any difference in emptying patterns between fast (A) and slow (B) emptying liquid meals using different techniques. Drink A emptied significantly faster from the stomach than drink $B$, as was expected (drink B had higher osmolality and a higher caloric content) regardless of the technique used. The difference in emptying between the two techniques proved to be consistent over the two drinks, as the geometric mean shows $(0.68$ for drink A, 0.64 for drink B). This leads to the conclusion that scintigraphy gives an emptying rate 0.7 times slower than double sampling for liquid meals, irrespective of whether they are slow or fast emptying. This finding of an underestimate of the gastric emptying rate with the scintillation technique has also been reported by several others. From studies using models of the stomach and on the basis of theoretical considerations, Lawaetz and Dige-Peterson ${ }^{16}$ describe an overestimate of the drink volume in the stomach by $10 \%$ when using scintigraphy. Sutton $e t a l^{17}$ compared gastric emptying rates when using scintigraphy and an epigastric impedance method and found scintigraphy gave an emptying rate $15 \%$ slower than epigastric impedance. This is considered to be primarily due to gastroduodenal overlap and scattering of radiation from the gut. However, individual variation, as indicated by the large $95 \%$ limits of agreement ( 1.56 to 0.30$)$ of the geometric mean, has to be taken into account. These wide limits might be due to the small sample size and the large coefficient of variation in the techniques used. ${ }^{16-22}$ Comparison of the two techniques should therefore not be made from individual data but should be based on group means. This work was partially sponsored by an Isostar Research Grant Grant. JBL is supported by a grant from Rorer Health Care Ltd, Gastbourne, UK.

We thank D Forrest, H G Gemmell, F W Smith (Department of Nuclear Medicine, Aberdeen Royal Infirmary), and A D M Kester (Department of Medical Informatics and Statistics, University of Limburg) for their assistance in this study.

1 Hunt JN, Spurrel WR. The pattern of emptying of the human stomach. F Physiol (Lond) 1951; 113: 157-68.

2 George JD. New clinical method for measuring the rate of gastric emptying: the double sampling technique. Gut 1968; 9: $237-42$.

3 Hunt JN. A modification to the method of George for studying gastric emptying. Gut 1974; 17: 812-3

4 Beckers EJ, Rehrer NJ, Brouns F, Ten Hoor F, Saris WHM. Determination of total gastric volume, gastric secretion and residual meal using the double sampling technique of George. Gut 1988; 29: 1725-9.

5 Horton RE, Ross FGM, Darling GH. Determination of the emptying time of the stomach by the use of enteric coated barium granules. BMF 1965; 1: 1537-9.

6 Harvey RF, Mackie DB, Brown NJG, Kelling DH, Davies WT. Measurement of gastric emptying time with a gamma camera. Lancet 1970; i: 16-8.

7 Collins PJ, Horowitz M, Cook DJ, Harding PE, Shearman DJC. Gastric emptying in normal subjects - a reproducible technique using a single scintillation camera and computer technique using a single scintill

8 Avill R, Mangnall YF, Bird NC, Brown BH, Barber DC, Seagar AD, et al. Applied potential tomography. A new noninvasive technique for measuring gastric emptying. Gastroenterology 1987; 92: 1019-26.

9 McClelland GR, Sutton JA. Epigastric impedance: a noninvasive method for the assessment of gastric emptying and motility. Gut 1985; 26: 607-14.

10 Tothill P, McLoughlin GP, Heading RC. Techniques and errors in scintigraphic measurements of gastric emptying. f Nucl Med 1978; 19: 256-61.

11 Rehrer NJ, Beckers EJ, Brouns F, Ten Hoor F, Saris WHM. Exercise and training effects on gastric emptying of carbohydrate beverages. Med Sci Sports Exerc 1989;21: 540-9.

12 Goo RH, Mooe JG, Greenberg E, Alazraki NP. Circadian variation in gastric emptying of meals in human. Gastroenterology 1987; 93: 515-8.

13 Elashoff JD, Reedy TJ, Meyer JH. Analysis of gastric emptying data. Gastroenterology 1982; 8: 1306-12.

4 Smith JL, Jiang CL, Hunt JN. Intrinsic emptying pattern of the human stomach. Am $\mathcal{F}$ Physiol 1984; 246: 959-62.

15 Bland JM, Altman DG. Statistical methods for assessing agreement between two methods of clinical measurement. Lancet 1986; i: $307-10$.

16 Lawaetz O, Dige-Petersen H. Gastric emptying of liquid meals: validation of the gamma camera technique. Nucl Med Commun 1989; 10: 353-64.

17 Sutton JA, Thompson S, Sobnack R. Measurement of gastric emptying rates by radioactive isotope scanning and emptying rates by radioactive isotope scan impedance. Lancet 1985 ; i: $898-900$.

18 Glowniak JV, Wahl RL. Patient motion artifacts on scintigraphic gastric emptying studies. Radiology 1985; 154: 537-8.

19 Christian PE, Datz FL, Sorenson JA, Taylor A. Technical factors in gastric emptying studies. F Nucl Med 1983; 24: 264-8.

20 Christian PE, Moore JG, Sorenson JA, Coleman RE, Weich DM. Effects of meal size and correction technique on gastric emptying time: studies with two tracers and opposed detectors. F Nucl Med 1980; 21: 883-5.

21 Tothill P, McLoughlin GP, Holt S, Heading RC. The effect of posture on errors in gastric emptying measurements. Phys Med Biol 1980; 25: 1071-7.

22 Beckers EJ, Rehrer NJ, Saris WHM, Brouns F, Ten Hoor F, Kester ADM. Daily variation in gastric emptying when using the double sampling technique. Med Sci Sports Exerc 1991; 23: 10 . 